\title{
COMUNIDADES TRADICIONAIS E ÁREAS DE PRESERVAÇÃO: DESAFIOS PARA A ARTICULAÇÃO ENTRE JUSTIÇA SOCIAL E PRESERVAÇÃO AMBIENTAL NO PARQUE NACIONAL DA CHAPADA DIAMANTINA $^{2}$
}

\author{
TRADITIONAL COMMUNITIES AND PRESERVATION AREAS: CHALLENGES FOR \\ ARTICULATION BETWEEN SOCIAL JUSTICE AND ENVIRONMENTAL PRESERVA- \\ TION IN THE CHAPADA DIAMANTINA NATIONAL PARK
}

\begin{abstract}
Resumo:
O presente artigo tem como objetivo aprofundar as reflexões sobre os desafios encontrados para a articulação entre justiça social e preservação ambiental nos casos de sobreposição territorial entre comunidades tradicionais e Unidades de Conservação (UC). Por meio de um estudo de caso sobre o Parque Nacional da Chapada Diamantina, o texto apresenta o panorama dos direitos das populações tradicionais no Brasil e na América Latina, as transformações operadas no sentido de identidade das comunidades rurais e como os temas justiça social e reconhecimento contribuem nas reflexões sobre o conflito socioambiental em questão. A pesquisa realizada aponta que, embora a Constituição Federal brasileira e outras leis e decretos garantam direitos específicos a grupos sociais tradicionais, dialogando com as estratégias de um constitucionalismo plurinacional adotado por alguns países sul-americanos, essas orientações não se efetivam nos casos em questão. Os obstáculos para a efetivação de direitos se apoiam na dualidade que se estabelece entre mundo formal e informal, comprometendo a estabilidade institucional e o funcionamento dos acordos. As estratégias para a superação de tais obstáculos, assim como de (re)ação e resistência das comunidades afetadas aos seus territórios serão aspectos abordados no decorrer do texto.

Palavras-chave: Conflitos socioambientais. Comunidades tradicionais. Parque Nacional da Chapada Diamantina.

1 Doutora em Ciências Sociais pelo Universidade Federal da Bahia. Docente e ativista socioambiental na Chapada Diamantina.E-mail: mariamedradon@gmail.com.

2 O presente artigo integra parte da pesquisa de doutorado da autora, defendida em março de 2018, vinculada ao Programa de Pós-Graduação em Ciências Sociais da Universidade Federal da Bahia.
\end{abstract}




\begin{abstract}
:
This article provides some reflections on the challenges found for the articulation between social justice and environmental preservation in cases of territorial overlap between traditional communities and Conservation Units. This case study of the Chapada Diamantina National Park presents the panorama of the rights of traditional populations in Brazil and Latin America, the transformations made in terms of identity of rural communities, and how the themes "social justice" and "recognition" contribute to the debate on the socio-environmental conflict in question. The research shows that, although the Brazilian Federal Constitution and other laws and decrees guarantee specific rights to traditional social groups, dialoguing with the strategies of a plurinational constitutionalism adopted by some South American countries, these guidelines are not effective in the cases in question. The obstacles to ensuring rights are based on the duality established between the formal and informal world, compromising the institutional stability and the functioning of agreements. Strategies for overcoming such obstacles, as well as the (re)action and resistance of affected communities to their territories will be addressed throughout the text.
\end{abstract}

Keywords: Socio-environmental conflicts. Traditional communities. Chapada Diamantina National Park.

\title{
INTRODUÇÃO
}

Situado no estado da Bahia, Brasil, o Parque Nacional da Chapada Diamantina (PNCD), uma Unidade de Conservação de Proteção Integral, foi criado em setembro de 1985 pelo Decreto $n^{\circ}$ 91.655. Sua criação foi um elemento bastante importante no aumento da visibilidade desse território no cenário turístico nacional e internacional, provocando profundas mudanças na vida dos habitantes do seu interior e do seu entorno.

Embora previsto no referido Decreto o prazo de quatro anos para edição do Plano de Manejo do Parque, normatizando o uso público e a forma de gestão da Unidade em conformidade com o Sistema Nacional de Unidades de Conservação (SNUC), importante instrumento que integra a legislação ambiental brasileira, tal documento somente foi publicado em 2009. A participação de agências governamentais e da sociedade civil através da formação do Conselho Consultivo do PNCD e de suas reuniões periódicas para a discussão de temas relacionados ao Parque foi um elemento que marcou a construção do Plano de Manejo.

Após finalizado, a implementação das normas apresentadas pelo Plano de Manejo se deparou com alguns desafios para o Órgão Gestor do Parque. Um deles é referente à permanência das comunidades no seu interior, que contra- 
ria as orientações dadas pelo Sistema Nacional de Unidades de Conservação (SNUC, 2000), no qual o Plano de Manejo está fundamentado. A determinação é de indenização e realocação dessas pessoas para outros lugares.

Contudo, encontra-se um conflito de direitos quando identifica-se que tais comunidades são assistidas por diferentes leis e decretos que, em alguns aspectos, se contrapõem à legislação ambiental. Destacamos aqui o caso da comunidade Fazenda Velha, já reconhecida pelo Estado brasileiro como remanescente de quilombo e, como tal, tem o direito à propriedade definitiva da terra que ocupa. De acordo com a Constituição Federal de 1988, no Ato das Disposições Constitucionais Transitórias, em seu art. 68, "aos remanescentes das comunidades quilombolas que estejam ocupando suas terras, é reconhecida a propriedade definitiva, devendo o Estado emitir-lhes os títulos respectivos".

Também, outras comunidades, uma vez reconhecidas como tradicionais, têm o amparo do Decreto $n^{\circ}$. 6.040/07, que institui a Política Nacional de Desenvolvimento Sustentável dos Povos e Comunidades Tradicionais (PNPCT, 2007) e visa apoiar grupos sociais no reconhecimento e na consolidação dos seus direitos territoriais, sociais, ambientais, econômicos e culturais, com respeito à sua identidade, suas formas de organização e suas instituições. Ainda que o citado decreto não garanta a permanência das pessoas no interior de áreas de proteção integral, entre os seus objetivos específicos destaca-se "solucionar e/ ou minimizar os conflitos gerados pela implantação de Unidade de Conservação de Proteção Integral em territórios tradicionais e estimular a criação de Unidades de Conservação de Uso Sustentável".

Nesse contexto, este artigo pretende desenvolver algumas reflexões sobre a forma de atuação do governo brasileiro em relação ao conflito socioambiental que se apresenta, tendo como estudo de caso o Parque Nacional da Chapada Diamantina. Parte da reflexão sobre as novas constituições latino-americanas que se constituíram no decorrer da década de 1980, possibilitando avanços no reconhecimento territorial de populações originárias e negras, incorporando novos instrumentos de reconhecimento dos direitos das populações tradicionais. Em seguida, analisa a complexidade do conflito territorial vivenciado entre comunidades nativas e Unidades de Conservação, focando no sentido da identidade "tradicional" como elemento de mobilização social em prol de justiça social e reconhecimento na contemporaneidade. Por fim, busca identificar os elementos que permitem a (re)existência das comunidades tradicionais em seus territórios e as alternativas de superação do conflito em questão. 


\section{SOBRE OS DIREITOS DAS POPULAÇÕES TRADICIONAIS NA AMÉRI- CA LATINA E NO BRASIL}

Para a compreensão do conflito em questão, é importante refletir sobre a trajetória histórica das formações nacionais latino-americanas, considerando o processo de expropriação territorial e exclusão social que as populações nativas vivenciam desde a colonização até a contemporaneidade. A expansão do capitalismo e a necessidade de domínio constante de novos territórios têm trazido insegurança e constante ameaça aos modos de vida dessas populações tradicionais. Contudo, avanços significativos nas legislações nacionais latino-americanas a partir da década de 1980 têm trazido novas possibilidades de resistência e enfrentamento, enfatizando o multiculturalismo como estratégia de respeito a diferença.

De acordo com Rocha (2015), a orientação multiculturalista foi significativamente difundida nas novas constituições latino-americanas, dando espaço para a criação de Estados plurinacionais, sendo pioneiras as constituições da Guatemala, em 1986, e da Nicarágua, em 1987. Anos depois, as novas constituições da Colômbia, em 1991, e Venezuela, em 1999, afirmaram a perspectiva dos direitos pluriétnicos salvaguardados nos territórios nacionais, dando autonomia às formas de autogestão aos diferentes grupos culturais originários.

Ainda que não seja uma nação pluriétnica, o Brasil assegura direitos diferenciados aos povos originários e afrodescendentes, como o direito à terra aos grupos sociais que foram marginalizados, excluídos ou deportados de seus territórios quando das investidas coloniais ocorridas a partir do final do século XV. Como forma de reconhecimento desses grupos, no processo indenitário brasileiro, e de reparo às injustiças das quais foram vítimas, a especificidade de tais populações foi abarcada na Constituição Federal de 1988. Os indígenas foram contemplados nos artigos 231 e 232 e os quilombolas no artigo 68 do Ato das Disposições Constitucionais Transitórias, com direito à garantias diferenciadas em relação aos territórios ocupados. No caso dos indígenas, a legislação brasileira reconhece a posse e o usufruto exclusivo da terra, contudo, reserva a propriedade à União. Aos quilombolas, a legislação confere a propriedade coletiva da terra, cuja titulação fica atribuída ao Estado. Destaca-se, ainda, no que se refere ao direito dos grupos em questão, os capítulos 215 e 216 dessa Constituição dedicados à proteção da cultura e ao respeito das diferentes formas de manifestação cultural, afirmando uma perspectiva multiculturalista, nos quais 
são garantidas também as formas de manifestação cultural de povos com identidades diferenciadas. (BRASIL, 1988)

Além de orientação multiculturalista, Santilli (2005) afirma que a Constituição Federal brasileira de 1988 foi bastante influenciada pela perspectiva ambientalista. No artigo 225, no capítulo VI, intitulado "Do Meio Ambiente", se detém à defesa do meio ambiente, afirmando que "Todos têm direito ao meio ambiente ecologicamente equilibrado, bem de uso comum do povo e essencial à sadia qualidade de vida, impondo-se ao poder público e à coletividade o dever de defendê-lo e preservá-lo para as presentes e futuras gerações". (BRASIL, 1988) Retifica-se, também, o comprometimento do país nas agendas internacionais voltadas para as estratégias de preservação ambiental.

Portanto, o novo século que se inicia mostra os limites e imperfeições da democracia representativa, indicando que não só em relação ao meio ambiente, mas nos contextos políticos de forma geral, se faz necessário dar respostas à crise de representação por meio de novas práticas de participação. Um exemplo está na obrigatoriedade da escuta aos povos e comunidades atingidos por diferentes empreendimentos, desde estradas, barragens e Unidades de Conservação, até a instituição de Conselhos Consultivos e Deliberativos, como fóruns de discussão que visam a dar suporte à gestão de áreas protegidas. Contudo, ainda que as discussões tenham surtido efeito na própria Constituição Nacional e na legislação ambiental, com o exemplo da inserção das Reservas Extrativistas na tipologia de Unidade de Conservação no Brasil, tais mudanças não foram capazes de superar os conflitos entre territórios tradicionalmente ocupados e a abordagem de Unidades de Conservação de Proteção Integral.

Em termos jurídicos nacionais, outras comunidades reconhecidas como tradicionais, além das indígenas e quilombolas, receberam o amparo do Decreto Federal $n^{\circ}$ 6.040, em 2007, que instituiu a Política Nacional de Desenvolvimento Sustentável dos Povos e Comunidades Tradicionais. Este decreto visa a apoiar esses grupos no seu pleito por reconhecimento dos seus direitos territoriais, sociais, ambientais, econômicos e culturais, considerando a sua particularidade identitária, suas formas de organização e modos de vida. Ainda que o decreto não indique uma solução clara para as sobreposições territoriais, o texto afirma "solucionar e/ou minimizar os conflitos gerados pela implantação de Unidade de Conservação de Proteção Integral em territórios tradicionais e estimular a criação de Unidades de Conservação de Uso Sustentável". (BRASIL, 2007)

Segundo o SNUC, em seu artigo 42: 
As populações tradicionais residentes em Unidades de Conservação nas quais sua permanência não seja permitida serão indenizadas ou compensadas pelas benfeitorias existentes e devidamente realocadas pelo Poder Público, em local e condições acordados entre as partes.

$[\ldots]$

Até que seja possível efetuar o reassentamento de que trata este artigo, serão estabelecidas normas e ações específicas destinadas a compatibilizar a presença das populações tradicionais residentes com os objetivos da unidade, sem prejuízo dos modos de vida, das fontes de subsistência e dos locais de moradia destas populações, assegurando-se a sua participação na elaboração das referidas normas e ações. (SNUC, 2000)

Os Termos de Compromisso são reafirmados pelo Decreto Federal de $\mathrm{n}^{\circ}$. 4.340, de agosto de 2002, que regulamenta artigos do Sistema Nacional de Unidades de Conservação. Consta em seu art. 39:

Enquanto não forem reassentadas, as condições de permanência das populações tradicionais em Unidades de Conservação de Proteção Integral serão reguladas por termos de compromisso, negociados entre o órgão gestor e as populações, ouvindo o conselho da Unidade de Conservação. (BRASIL, 2002)

Além das novas orientações que foram agregadas à legislação ambiental, a remoção destas populações também encontrou grandes dificuldades, em especial quando os direitos dos povos e das comunidades tradicionais foram fortalecidos com o Decreto Federal de $\mathrm{n}^{\mathrm{o}}$. 6.040, em 2007. O referido decreto institui a Política Nacional de Desenvolvimento Sustentável de Povos e Comunidades Tradicionais. Dentre os princípios da referida política, conforme consta no artigo primeiro, destaque-se:

o reconhecimento, a valorização e o respeito à diversidade socioambiental e cultural dos povos e comunidades tradicionais, levando-se em conta, dentre outros aspectos, os recortes etnia, raça, gênero, idade, religiosidade, ancestralidade, orientação sexual e atividades laborais, entre ou- 
tros, bem como a relação desses em cada comunidade ou povo, de modo a não desrespeitar, subsumir ou negligenciar as diferenças dos mesmos grupos, comunidades ou povos ou, ainda, instaurar ou reforçar qualquer relação de desigualdade. (BRASIL, 2007)

No artigo segundo, ressalta-se como principal objetivo

promover o desenvolvimento sustentável dos Povos e Comunidades Tradicionais, com ênfase no reconhecimento, fortalecimento e garantia dos seus direitos territoriais, sociais, ambientais, econômicos e culturais, com respeito e valorização à sua identidade, suas formas de organização e suas instituições. (BRASIL, 2007)

Embora amplo e com poucas orientações de ações práticas para o alcance dos objetivos propostos, o Decreto Federal de $n^{\circ}$. 6.040 tem tido grande importância para a visibilidade e as lutas pelos direitos territoriais dessas populações que, em muitos casos, não possuem a propriedade formal de suas terras.

Não apenas as formulações e reformulações jurídicas sobre a permanência de comunidades nativas em Unidades de Conservação de Proteção Integral se apresentam como fatores determinantes na forma de lidar com os casos de sobreposição. É importante destacar a própria incapacidade do Incra (Instituto Nacional de Colonização e Reforma Agrária) em resolver a questão apresentada. No contexto do presente conflito, a realocação das comunidades depende de uma ação conjunta entre o Instituto Chico Mendes de Conservação da Biodiversidade (ICMBio), o Instituto Nacional de Colonização e Reforma Agrária (Incra) e outras entidades públicas municipais, estaduais e federais. Esse fato implica em uma articulação que não se faz presente no caso em questão. A falta de condições institucionais e interinstitucionais de levar adiante um processo de regularização fundiária em curto prazo é um fator importante que se apresenta como obstáculo à realocação.

É neste contexto de insegurança em relação à permanência na terra que o "ser tradicional" se posiciona como agente político na construção e afirmação de uma identidade. Manifesta características do próprio local, expressas nos modos de vida e nas formas de se relacionar com os territórios que fazem parte. Segundo Castells (2013), a identidade é definida como fonte de experiência de um povo; como processo de construção de significado com base em um atributo cultural, ou mesmo um conjunto de atributos culturais inter-relacionados. 
Com risco da realocação, a identidade desses grupos vem à tona como parte da reivindicação por sua permanência, não apenas para a geração atual, mas também a futura. Utilizando a tipologia construída por Castells (2013), percebe-se a luta travada pela identidade de resistência que, no caso estudado, poderia representar o próprio "ser tradicional", inserida em uma complexa disputa pela afirmação da legitimidade, ainda que esta seja constantemente remodelada pelas transformações sociais, culturais e econômicas. Também se faz presente no estudo em questão a identidade de projeto, como busca por alternativas de sustentabilidade por meio da formulação de projetos que articulem desenvolvimento comunitário e preservação ambiental.

O caso das populações nativas em Unidades de Conservação no Brasil se torna ainda mais instigante pelo fato da identidade dos grupos não estar definida, mas em construção, em busca de legitimidade ou mesmo de reconhecimento. Segundo a definição de comunidade tradicional encontrada no Artigo $3^{\circ}$ do Decreto Federal de ${ }^{\circ}$. 6.040:

grupos culturalmente diferenciados e que se reconhecem como tais, que possuem formas próprias de organização social, que ocupam e usam territórios e recursos naturais como condição para sua reprodução cultural, social, religiosa, ancestral e econômica, utilizando conhecimentos, inovações e práticas gerados e transmitidos pela tradição. (BRASIL, 2007)

A classificação de grupos sociais como tradicionais, em especial aqueles de raízes étnicas, como indígenas e quilombolas, conduzem a reflexões sobre os "novos direitos" incorporados na Constituição Brasileira de 1988, fortemente influenciados pelo multiculturalismo constitucional que se difundiu pela América Latina. Ainda que no caso brasileiro não se constitua como um Estado Plurinacional, tal como nas outras experiências latino-americanas, o reconhecimento pelo Estado de direitos específicos das populações indígenas e quilombolas que, historicamente, foram colonizadas e exploradas durante os processos de construção nacional, indicam como a questão das classificações sociais estão inseridas no campo jurídico. (ROCHA; SERRA, 2015)

Aproximando os aspectos apresentados à perspectiva teórica sugerida por Bourdieu (2007), pode-se analisar que a classificação de grupos sociais e a posição ocupada por cada um deles estão condicionadas à detenção de dois tipos de capital - o econômico e o cultural -, os quais se distribuem de forma desigual no conjunto das sociedades. Para cada classe de posição, há uma classe de habitus correspondente, ou seja, a forma que as estruturas são incorporadas 
aos indivíduos, compondo uma unidade de estilo de vida produzida pelos condicionantes sociais e associada à condição correspondente da posição de classe. A relação entre a questão identitária, na qual a questão étnica e a territorial aparecem como distintivas, e a situação de classe em que tais grupos se encontram suscita algumas reflexões sobre como as estruturas sociais são formadas. A existência de sistemas simbólicos que operam tanto como estrutura estruturada como estrutura estruturante, nos quais estão em jogo diferentes tipos de poder, é um importante referencial para compreender o caso em questão.

Seguindo a perspectiva de Bourdieu (2007), a classe pode ser compreendida como o resultado da luta pela classificação, tanto como luta política, mas também simbólica, para impor uma visão do mundo social na qual os instrumentos de distinção legitimam a cultura dominante. Diferentes classes e frações de classe estão envolvidas nessa luta simbólica, a qual é travada nos conflitos simbólicos da vida cotidiana. $\mathrm{O}$ autor destaca a importância do papel dos especialistas da produção simbólica - antropólogos, juristas e demais cientistas sociais - na definição ou caracterização do modo de vida de grupos específicos. Voltando o olhar do autor para as comunidades estudadas, a sua luta pela classificação de "tradicional" coloca em evidência o próprio modo de vida e sua continuidade, ainda que temporária, em determinado território.

A reação desses grupos à realocação, considerada um processo de desterritorialização forçada devido ao avanço de novas fronteiras que delimitam áreas de proteção ambiental, pode ser compreendida como luta pelo reconhecimento de formas de organização social distintas, que tem colaborado para a preservação de dado território, coadunando-se com os objetivos das áreas protegidas. A defesa dos laços materiais e simbólicos que fundamentam seus modos de vida, projetos de desenvolvimento e as teias de relações sociais que os sustentam permitem compreender a noção de território considerando as suas múltiplas escalas e inserindo em um contexto multiculturalista elementos que revelam a sua complexidade. Conforme afirma Ribeiro e Loiola (2009), a perspectiva multiescalar possibilita entender o território como espaço de interesses e teia de poderes que irão se refletir nas formas de pensar os projetos possíveis de desenvolvimento, o que impõe a necessidade de se repensar a relação entre o social e a natureza, assim como as escalas de tempo e espaço, levando em conta a diversidade de racionalidades presente em um mesmo território.

Apoiando-se nas análises de Ribeiro e Loiola (2009), a sobreposição de territórios de Unidades de Conservação e comunidades nativas revelam a necessidade de se pensar sobre as suas diversas dimensões e escalas, assim como as inúmeras percepções tanto das comunidades locais sobre si mesmas, quan- 
to de organismos nacionais e transnacionais referentes aos novos regramentos que regem as áreas protegidas. Como forma de conciliação de interesses, os projetos de desenvolvimento das comunidades, assim como seus modos de vida e de organização social, devem estar acordados com os princípios de preservação ambiental que fundamentam a existência da Unidade de Conservação e seus objetivos. Para que isso seja possível, é necessário o estabelecimento de compromissos baseados no entendimento comum e na confiança, elementos de grande importância no estabelecimento de relações de cooperação.

\section{DE NATIVOS A TRADICIONAIS: A IDENTIDADE COMO LUTA POR DIREITOS}

$\mathrm{O}$ argumento de haver uma identidade "tradicional" permeando as comunidades nativas, o que possibilita um status diferenciado nas negociações, é um elemento significativo na trama do conflito analisado neste artigo. A partir da disputa pelo reconhecimento de tal identidade, introduz-se uma perspectiva de direito coletivo, fundamentada na identidade de grupo, sob o argumento de que não se trata de uma luta de proprietários particulares isolados, mas de comunidades rurais que, além de reivindicarem o direito privado de propriedade (ou mesmo despossuídos do mesmo), se apoiam em uma perspectiva de construção coletiva do território, assim como das formas de gestão coletiva dos recursos naturais ali disponíveis.

Os diferentes termos utilizados na definição dos grupos sociais, assim como suas diferentes traduções presentes nos diversos documentos internacionais, se revelam como um elemento de destaque na compreensão de seu sentido que permanece como uma questão chave, sendo construído e reconstruído de acordo com as relações que se estabelecem seja no mundo formal, das normas, acordos e decretos, seja no mundo informal, das práticas cotidianas. Sobre esse tema, Diegues (2001) afirma que o debate sobre os termos populações nativas, tribais, indígenas e tradicionais não é apenas de conceito, mas de expressão nas diversas línguas. Como observa o autor, o termo indigenous, utilizado em muitos documentos internacionais não se refere apenas a "indígenas" no sentido étnico e tribal, mas sim a nativos de modo geral, evidenciando a pluralidade e as complexidades das definições e dos sentidos.

$\mathrm{Na}$ realidade latino-americana, é interessante perceber como essa definição também se constitui, permitindo que a reflexão seja aprofundada quanto à definição do ser "tradicional". Voltando o olhar à realidade argentina, é de 
grande importância os trabalhos desenvolvidos por Hocsman (2011; 2014) ao analisar a dinâmica de vida de comunidades campesinas andinas no que tange à sua caracterização, às suas vinculações étnicas e à forma com que estas lidam com seus territórios, assim como às políticas públicas desenvolvidas para estas populações. Na experiência argentina, o termo "populações tradicionais" não encontra sinônimo, gira em torno de "populaciones campesinas" ou "pueblos originários", concepções marcadas por elementos étnicos nos quais a identidade indígena está fortemente presente, ainda que não de forma exclusiva. $\mathrm{Na}$ visão do autor, o termo "campesino" aparece como uma palavra polissêmica: um modo de vida comunitário e fraterno que não interiorizou por completo as grandes frações da modernidade, tais como a mercantilização da natureza e a separação da sociedade política da sociedade civil.

A falta de um entendimento comum referente aos termos que definem as populações e comunidades que se fundamentam em um modelo tradicional de vida rural torna-se um obstáculo à garantia de direitos diferenciados para essas populações, como, por exemplo, a possibilidade de acordos para as suas permanências, ainda que temporárias, nas Unidades de Conservação de Proteção Integral. Conforme as considerações da pesquisa desenvolvida por Talbot (2016) referente ao tema dos Termos de Compromisso (TC) no Brasil, a necessidade de se afirmar a "tradicionalidade" de determinada comunidade como condição para se construir um TC é uma das dificuldades no estabelecimento de acordos.

Comunidades e povos "nativos" ou "tradicionais" expressam contradições e incertezas, sendo significativos os debates e as produções bibliográficas sobre o tema, em especial no campo das ciências humanas e sociais latino-americanas. A contraposição entre "tradicional" e "moderno" é um dos desafios na classificação e na própria defesa desses povos frente aos projetos de um desenvolvimento de vida conservador e excludente, que contempla a construção de estradas, hidrelétricas, assim como Unidades de Conservação, afetando diretamente as populações nos territórios.

A visão evolucionista do mundo na qual a humanidade passaria por etapas e a modernidade chegaria a todos expressa bem como o "tradicional" é pensado (e repensado) em um contexto contemporâneo. As formas múltiplas de definições em um mundo no qual as consequências da modernidade redundam em grande fluidez e transformações das identidades coletivas, explicitam as dificuldades das reivindicações de grupos sociais envolvidos em complexas relações de poder. (BAUMAN, 2001) 
Considerando a definição e legitimação da identidade como base de disputas, nas quais diferentes interesses estão presentes na luta pela classificação, é importante estar atento para que, ao analisar um dado grupo social, não seja utilizada a noção de identidade coletiva como algo sólido, fechado e apático em relação às relações de poder que estão envolvidas. De acordo com as lições de Bourdieu, Chamboredon e Passeron (2005), as definições/classificações sobre os grupos sociais devem ser observadas como elemento de reflexão crítica e não simplesmente aceitas pelo pesquisador. Nesse sentido, é necessário pensar sobre os interesses materiais e simbólicos que estão envolvidos, destacando o fato de o status de "tradicionais" estar em curso nas negociações sobre a resolução dos conflitos de sobreposição territorial.

É em meio a essa disputa de sentidos que se destacam as questões: quem são as "comunidades tradicionais" na contemporaneidade? Elas chegarão à pós-modernidade ou estarão fadadas a permanecerem como tradicionais para sempre? Qual o sentido geracional que esta classificação traz consigo? Na leitura realizada por Siqueira e Pinto, publicada em 2007, há mais de uma década atrás, as autoras afirmam que as "comunidades tradicionais" têm sido vítimas de uma desqualificação pela representação social hegemônica de sociedades altamente individualizadas. Termos como caboclos, sertanejos, ribeirinhos, dentre outros manifestam ideias relacionadas a um entendimento dessas populações como um estorvo ao progresso, em meio ao qual a modernidade avançada deve o mais rapidamente adentrar.

A disciplina que o trabalho moderno exige, o consumo que transcende a necessidade, a mercantilização da produção e a monetarização da troca de bens são elementos que Siqueira e Pinto (2007) apontam como decisivos na pressão por uma transformação do tradicional, então percebido como velho e ultrapassado, idealizando-se o moderno como novo e avançado. Contudo, as práticas fundamentadas na hierarquização entre moderno e tradicional têm sido questionadas e são alvos de mudanças na própria ação governamental, como foi mencionado nos exemplos supracitados da Política Nacional de Desenvolvimento Sustentável dos Povos e Comunidades Tradicionais (PNPCT) e da criação de Reservas Extrativistas (Resex), modalidades aceitas como um tipo de Unidade de Conservação. Esses são os elementos apontados pelos autores como fortalecedores da organização comunitária e do reconhecimento da importância dos saberes tradicionais para o sistema de gestão compartilhada dos recursos naturais.

Ainda que a definição mais precisa de comunidades nativas encontre desafios em se firmar, em um contexto de complexificação das identidades co- 
letivas, observa-se que muitas formas de organização social presentes nas Unidades de Conservação, assim como em outras áreas protegidas, pela maneira de lidar com os seus territórios, apresentam características que possibilitam percebê-las como parceiras das estratégias de conservação. Conforme a pesquisa de campo revelou, quando questionados sobre o papel das comunidades nativas na gestão das Unidades de Conservação, as respostas dos analistas ambientais entrevistados explicitaram a possibilidade de articulação e parcerias como formas de avançar na gestão das áreas protegidas, encontrando nas populações residentes apoio para o enfrentamento de outros interesses que poderiam impactar negativamente na própria preservação:

Nas Resex isso é bem claro [...]. Em alguns lugares ela [a comunidade] ajuda a manter uma distância desses outros setores mais voltados para a destruição, né. Especulação imobiliária, grilagem de terra, onde tem essas comunidades, existe essa resistência. (Entrevistado 1, 2015)

Quando você tem populações tradicionais dentro da Unidade de Conservação, essas políticas têm muito mais dificuldades de serem implementadas. Quando você não tem ninguém dentro da Unidade de Conservação, o cara só vai brigar com o Ibama e com a gente, aí para ele é mais fácil, entendeu? Inclusive se os interesses do governo permanecerem em apoiar esses royalties, acho que eles não vão querer gente dentro de Unidades de Conservação; o social está indo por água abaixo. (Entrevistado 3, 2015)

Pode-se afirmar que a transição da condição do "ser nativo" para "ser tradicional" está presente nos conflitos que se manifestam nos campos político, econômico, ambiental e cultural. Aceitar a identidade de "ser tradicional" se contraporia aos avanços dos modos de modernização capitalista no campo, assegurando uma proteção ambiental mais adequada e responderia à necessidade de justiça social. Esta abordagem oferece aos atores tanto desvantagens, relacionadas à produção de estigma, como vantagens, permitindo que certos grupos sejam contemplados em políticas e planos que os favoreçam pela capacidade de trazerem benefícios para a preservação do local. No entanto, esses percursos não podem ser pré-determinados e os caminhos que podem indicar são imprevisíveis, tendo em vista a fluidez e as rápidas transformações hoje em todos os domínios. Ser "tradicional" na pós-modernidade representa uma complexa teia de relações que deve ser vista de maneira crítica e multidimensional, 
considerando tanto as subjetividades que permeiam as formas e lógicas de ação dos indivíduos, quanto os condicionantes impostos pelas estruturas sociais de hierarquização e desigualdade.

Quanto ao problema identitário, as contribuições de Stuart Hall (2005) são bastante pertinentes. $O$ autor afirma que as identidades modernas estão sendo "descentradas", ou seja, deslocadas ou fragmentadas, associadas a uma mudança estrutural que transformou as sociedades modernas no final do século XX, possibilitando diferentes "posições de sujeito". Na perspectiva do autor, a fragmentação e pluralização das identidades apresentam consequências significativas, como a manifestação de identidades contraditórias que atuam tanto fora, na sociedade, quanto dentro, na cabeça de cada um. Há também as identificações rivais e deslocantes advindas da erosão da "identidade mestra" de classe e da emergência de novas identidades, pertencentes à nova base política definida pelos novos movimentos sociais; ademais, há a mudança de uma política da identidade para uma política da diferença.

No caso empírico em questão, as "posições de sujeito" utilizam-se da possibilidade das comunidades nativas se firmarem no conflito por meio de uma identidade "tradicional" posicionada na luta por direitos, aproximando-se de uma forma de "identidade de resistência", conforme propõe Castells (2013), uma forma de ação coletiva. Por outro lado, a afirmação de uma identidade garante, simultaneamente, uma sensação de segurança - ser incluído em um grupo de iguais - e de aprisionamento a uma definição fechada em um mundo tão fluido. Segundo orientações da própria política ambiental, tal visão se configura como a possibilidade, ainda que provisória, para a permanência das comunidades nos territórios em contestação.

A formulação da identidade "tradicional" em um mundo globalizado, em que as constantes transformações tecnológicas modificam as noções de espaço e tempo, convida a uma reflexão sobre as dificuldades de ainda se manter um padrão homogêneo de classificação a uma dada coletividade, de uma só referência identitária. Segundo Bauman (2005), seguindo a perspectiva de Hall (2005), a globalização é um elemento de grande importância para a compreensão da fluidez dos laços sociais, representando uma longa transformação. Portanto, identidade, segundo o autor, não pode ser compreendida como algo pronto e acabado: 
Numa sociedade que tornam incertas e transitórias as identidades sociais, culturais e sexuais, qualquer tentativa de "solidificar" o que se tornou líquido por meio de uma política de identidade levaria inevitavelmente o pensamento crítico a um beco sem saída. (HALL, 2005, p. 12)

De acordo com a citação acima, a busca por uma afirmação identitária se configura como uma tarefa para alcançar o impossível, uma vez que não é sólida e nem garantida, evidenciando uma luta contra a dissolução e a fragmentação. Este tipo de conflito é marcado por dois elementos que caminham juntos: a debilidade do conjunto de crenças, símbolos e normas que une todos os membros da sociedade politicamente organizada e a riqueza, densidade e diversidade dos símbolos identitários alternativos que compõem as coletividades.

$\mathrm{Na}$ descrição dessas formas de vida e trabalho, inclusive as relações familiares de laços fortes, é possível perceber similitudes entre o "nativo" e o "tradicional", identidades mantidas e transformadas em um mundo no qual padrões tradicionais de vida estão inseridos na dinâmica de um mundo globalizado. Neste mundo, as políticas nacionais e internacionais, tanto de preservação do meio ambiente quanto de defesa da diversidade cultural, encontram elementos conflitantes, que opõem interesses e lógicas de cooperação, exigindo a realização de acordos e práticas convergentes.

A classificação como tradicional, no entanto, não garante direitos com certeza. O caso dos grupos sociais já legitimados como tradicionais no Brasil - indígenas e quilombolas - apresenta uma situação ainda conflitiva. Mesmo tendo direitos territoriais firmados na Constituição Federal, na prática, se encontram muito aquém no que se refere aos direitos atendidos. $\mathrm{O}$ estudo de $\mathrm{Vi}$ tale (2015) sobre as comunidades amazônicas indica que, embora as conquistas legais nacionais e internacionais tenham avançado, com decisões tomadas no âmbito de cada Estado Nacional, restritas ou condicionadas por fatores externos, há um déficit de sua efetividade face às tensões empresariais e governamentais no nível local, regional e nacional. Esse descompasso conduz a questionamentos de como devem ser encaminhadas as questões referentes ao deficit democrático na arena transnacional. A autora argumenta que as políticas internacionalmente organizadas, em especial aquelas voltadas aos temas do meio ambiente, desenvolvimento e direitos humanos, não são acompanhadas de transparência, prestação de contas, monitoramento e avaliação contínua. 


\section{JUSTIÇA SOCIAL E RECONHECIMENTO}

Como já foi identificado anteriormente, o conflito entre comunidades nativas e Unidades de Conservação toma três dimensões. A primeira é relacionada ao direito privado da propriedade da terra, que é vista como um bem público, sem que o Estado tenha realizado as devidas indenizações. A segunda dimensão é sobre o direito coletivo relativo à forma e aos critérios de utilização das áreas comuns que integram os territórios comunitários. Por fim, a terceira dimensão é a do direito público, relativo à normatização de uma área de proteção, atendendo a direitos difusos relacionados ao meio ambiente.

Estas três dimensões permitem que o conflito observado se refira não apenas a proprietários individuais, mas a grupos sociais específicos, com características que podem defini-los (ou não) como comunidades "tradicionais"; uma classificação que pode situá-los em um status diferenciado no embate em questão. $O$ "ser tradicional" e as relações sociais com base nessa identidade conduzem a reflexões sobre as formas de solidariedade social na contemporaneidade, considerando o impacto da modernidade nas configurações de grupos sociais específicos. Para Habermas (1988), sobre a base da teoria durkheimiana, a sociedade capitalista se fundamenta na transição operada entre uma forma de solidariedade para outra, modificando as bases de integração social e das formas de vida. Enquanto nas sociedades primitivas a integração se dá por meio de um consenso normativo básico, nas sociedades complexas a integração entre os atores se dá através de uma conexão sistêmica de multiplicidades de ação funcionalmente especificadas.

A formação de uma moral capaz de servir de base à integração social pode ser alcançada, segundo o autor, por meio de duas possibilidades: através de um consenso assegurado normativamente e comunicativamente, ou mediante uma regulação não normativa de decisões particulares, situadas além da consciência dos atores. Tais alternativas de constituição da integração social levam Habermas (1988) a compreender a sociedade simultaneamente como o "mundo da vida" de um grupo social, assim como o "sistema" de ações. Mundo da vida e sistema, conceitos chave de sua obra, são essenciais para entender como o autor articula essas duas esferas na construção de uma perspectiva teórica da ação social fundamentada no agir comunicativo.

O mundo da vida, segundo Habermas (1988), é compreendido como

contexto da ação comunicativa, processo cooperativo de interpretação em que 
o mundo objetivo, o mundo social e o mundo subjetivo acontecem simultaneamente. É na prática comunicativa cotidiana que se reproduz a cultura, a sociedade e a pessoa, mantendo a tradição e a renovação do saber cultural associadas com a integração social, a criação de solidariedade e a formação de identidades pessoais. Se nas sociedades primitivas o mundo da vida é coextensivo a um sistema social pouco diferenciado, este vai se transformando progressivamente, passando a se expressar como um subsistema com a capacidade de influenciar a consistência do sistema social em seu conjunto.

O processo de racionalização do mundo da vida, articulado com o potencial de racionalidade que a ação comunicativa traz, possibilita estabelecer novos níveis de diferenciação sistêmica que só podem ser alcançados quando a racionalização se der com orientações valorativas cada vez mais formais. Contudo, o processo de racionalização pode acarretar crises sobre a reprodução social, tais como a perda de sentido, anomia e alienação. (HABERMAS, 1988)

Por meio das concepções de sistema e mundo da vida, as contribuições de Habermas (1988) seguem no sentido de compreender como a interação social interfere nas dinâmicas sociais, indicando que a razão instrumental não é a única forma de racionalidade no capitalismo, mas coexiste junto com a razão comunicativa. A formação linguística passa a especializar-se em determinados aspectos de validez e de hierarquização dos processos de entendimento. Tal hierarquia se manifesta nas estratificações decorrentes de relações de poder, em que a autoridade política ganha legitimidade em sobreposição às demais autoridades tradicionais, alterando a consciência dos membros em relação à ordem jurídica. A abordagem desse autor sobre a forma que o agir comunicativo se manifesta dialeticamente, tanto nos sistemas sociais como no mundo da vida, permite explicar as estruturas de poder descentralizadas. Portanto, as duas formas de racionalidades que convivem juntas - a instrumental e a comunicativa - dão sustentação ao questionamento da neutralidade ética da ordem jurídica e política, cujos agentes são tanto constituidores como constituídos pelas relações desiguais de poder.

As relações desiguais de poder são expressas, entre outras, nas desigualdades de privilégios estatais entre as diferentes formas de organização social que coincidem em um mesmo território nacional, contrariando os anseios por um reconhecimento recíproco. Ainda que o universalismo dos princípios jurídicos indique uma tentativa de compartilhamento racional, uma hierarquia de saberes se faz presente na formulação e no controle das regras, o que afasta a ideia de neutralidade dos princípios universais adotados. 
Nas análises sobre a teoria habermasiana, Mattos (2006) comenta a passagem das hierarquias sociais que, antes, baseadas no nascimento, agora, vinculam-se a um novo elemento com lugar central no campo dos conflitos sociais: o conhecimento. $O$ confronto de lógicas na construção das noções de preservação evidencia que, dentro da estrutura de poder do conhecimento constituído na modernidade ocidental, as formas de saberes tradicionais são subjugadas ao conhecimento científico, o que gera dificuldades para que a consolidação de acordos aconteça dentro de um jogo equilibrado de poder e de reconhecimento mútuo.

Ao transpor tais reflexões teóricas aos casos empíricos de sobreposição territorial observados no presente estudo, percebem-se, nas negociações entre os interesses pleiteados pelas comunidades e aqueles concernentes às Unidades de Conservação, as disputas de poder que estão em jogo na formulação dos planos de manejo e das orientações técnicas sobre a preservação ambiental, em que se articulam razão instrumental e razão comunicativa em construções discursivas que reafirmam o papel privilegiado do saber técnico (como preservar o meio ambiente) enquanto detentor dos recursos aceitáveis de reconhecimento e legitimidade.

Segundo Habermas (2004), um grande desafio da contemporaneidade é como as constituições modernas, com orientação positivista e individualista do Estado de direito, fundamentadas na ideia de universalidade, podem dar conta das lutas por reconhecimento das identidades de minorias ou coletivas que se manifestam de diferentes maneiras em um contexto multiculturalista, e reivindicam a legitimidade de novas formas de conhecimento sobre a formação dos sujeitos, os quais, muitas vezes, são subjugados ao conhecimento consagrado e dominante. Tais reivindicações assentam-se não apenas no pleito pela igualdade de condições sociais de vida, mas também no anseio pela integridade de formas de vida e tradições de grupos, incluindo as suas maneiras de fazer e saber com as quais os seus membros se identificam.

A adaptação do Estado a essas novas reivindicações implica em uma transformação paradigmática do direito, em que as tradições culturais e formas de vida podem se reproduzir, possibilitando a internalização de novos valores na estrutura de personalidade dos indivíduos. Contudo, as relações econômicas desiguais, reflexo da má distribuição de renda, expõem a situação de exclusão social ou de inclusão precária de tais atores, pois estes não gozam da autonomia necessária, já que não acessam, em grande parte dos casos, direitos fundamentais, como saneamento, educação, saúde etc. Dessa forma, não lhes é permitido entenderem a si mesmos como atores de direito e cidadãos. 
A incompatibilidade da permanência das populações residentes nas Unidades de Conservação de Proteção Integral com a legislação ambiental vigente, assim como a inoperância deliberada do Estado frente às questões sociais e aos processos de indenização e realocação tornam incerto o futuro desses atores e, também, levantam o tema sobre como vingam as orientações jurídicas no Estado democrático de direito. Considerando a realidade das desigualdades sociais e diferenças culturais, cujos códigos e normas formais são compartilhados e assimilados de diferentes formas pelos grupos presentes, é importante analisar os desafios que a diversidade social impõe às regras democráticas e às orientações individualistas do direito na contemporaneidade.

Retornando a Habermas (2004, p. 253), o reconhecimento das diferenças traz à tona a questão da neutralidade ética da ordem jurídica e da política, uma vez que "toda ordem jurídica é também expressão de uma forma de vida particular, e não apenas o espelhamento do teor universal dos direitos universais", ainda que razões éticas desempenhem também um papel de "aconselhamento e justificação" das decisões políticas. Assim, a coexistência equitativa dos diferentes grupos socioculturais não pode ser garantida por um tipo de direito criado para o atendimento de pessoas individuais universais, sendo necessário avançar sobre os regramentos legais para atender novas demandas que surgem em contextos de expressões multiculturais e de luta por reconhecimento, envolvendo as esferas emotiva, jurídica, moral e de estima social.

Um aspecto que merece destaque refere-se ao fato de os confrontos desencadeados pela luta por reconhecimento não serem estáticos, mas mudarem de sentido e se formarem de acordo com a dinâmica de transformação das próprias identidades culturais que tentam se afirmar. Segundo Honneth (2011), a coexistência equitativa de formas de vida implica tanto na possibilidade dos grupos se confrontarem com o seu universo de origem, dando continuidade aos modos de vida perpetuados pela tradição, quanto de transformá-lo e distanciarem-se ou mesmo romperem com seus imperativos. As transformações e continuidades operadas nas formas de vida dos grupos sociais, para que sejam reconhecidas e legitimadas, implicam na necessidade de garantias jurídicas que se adaptem às novas formas e condições de vida. Delineia-se, assim, a necessidade de constantes mudanças que as lutas por reconhecimento conseguem aportar para o Estado democrático de direito.

Para os dilemas apontados, novas conexões podem ser estabelecidas entre um novo paradigma de conservação, a etnoconservação, e os conflitos sociais contemporâneos, nos quais as identidades sociais grupais substituem os interesses de classe como mobilizador político, conforme aporta a teoria do 
reconhecimento. Para Alexandre (2002), no caso das sobreposições territoriais de áreas protegidas, a etnoconservação surge como alternativa que enfatiza o reconhecimento de populações localizadas, permitindo uma política de meio ambiente possível, que encontra desafios políticos de resistência e integração ao mundo globalizado. A possibilidade de articulação entre etnoconservação e reconhecimento de comunidades nativas confere outra lógica para a gestão das áreas protegidas, com a participação desses grupos na construção e operação das estratégias de preservação ambiental, alimentando um processo de autorrealização da comunidade.

\section{CONSIDERAÇÕES FINAIS}

Imersa em um conflito de regras e normas referentes ao território, deixando transparecer as relações desiguais de poder, a situação investigada nesta pesquisa enseja reflexões sobre determinadas formas de ação (e reação) frente à sobreposição territorial e aos embates que dela emergem, assim como revela os diversos interesses que estão em jogo no percurso da disputa.

Embora o Brasil adote tanto nos seus princípios constitucionais, quanto nas legislações específicas, uma perspectiva multicultural e de reconhecimento das identidades subjugadas e desfavorecidas na história nacional, na prática essa orientação encontra obstáculos para serem seguidas. Replicando as ideias de Wanderley Guilherme dos Santos (1994) para o caso em estudo, o híbrido institucional marca a cultura política brasileira e contrapõe o mundo da vida (mais informal, presentes nas práticas cotidianas) aos mecanismos formais de regulação (das leis e regras formais) que orientam a dinâmica do território, visando à indenização e realocação das populações do local. Contudo, enquanto o que afirma a lei não é cumprido, sem haver sequer uma previsão para isso, observa-se que o excesso de comandos, diretrizes e planos, ainda que estes pretendam regular comportamentos individuais que espontaneamente seriam insuficientes para promover a ordem social, gera externalidades negativas, em especial quando as normas não são cumpridas, violando a credibilidade da lei. (SANTOS, 1994)

O autor enfatiza que, em situações de híbrido institucional, o conflito social tende a ser dissimulado frente às dificuldades que encontra em estabelecer relações de confiança e soluções entre as instituições públicas e os indivíduos. Apoiando-se nas contradições expostas por Santos (1994), Laniado (2001a) analisa a forma como se estruturam os sistemas de troca e reciprocidade que 
compõem as normas sociais e a institucionalização da política no Estado, por meio das agências públicas e da legislação, assim como a capacidade dos indivíduos de aderir a elas para garantir os compromissos sociais na coletividade. $\mathrm{O}$ híbrido institucional enfraquece os sentidos de liberdade, obrigação e confiança da comunidade política, elementos base dos sistemas de reciprocidade modernos, bem como a confiança nas leis e instituições para solucionar conflitos. A autora considera que o híbrido institucional no sistema político e no funcionamento do Estado produz ambivalência entre direitos e obrigação, combinando valores sobre o tradicional e o moderno de modo particular na cultura política e social nacional, muitas vezes postergando deliberações e soluções, e frustrando os atores.

É possível afirmar que as ambivalências que se destacam na cultura política brasileira, (des)orientadas pelo híbrido institucional, podem repercutir nos territórios em questão, onde uma duplicidade de sistemas de normas convive em um mesmo espaço socioambiental. A incapacidade do Estado brasileiro em realizar a regularização fundiária de tais áreas protegidas por meio de indenizações, realocações e valores acordados com os proprietários, moradores ou não do local, é um ponto relevante do conflito que se dá no âmbito do direito público, direito privado e do direito coletivo.

A ambiguidade entre a área delimitada e a efetivação da regularização fundiária cria um complexo sistema de lentas negociações, afetando a visão dos nativos sobre justiça e injustiça, assim como dos demais membros da sociedade civil e das instituições que operam os instrumentos legais para administrar o conflito. Enquanto não se efetivam as orientações previstas, proprietários ou ocupantes migram ou permanecem sob a ameaça da realocação. Por um lado, lentamente, incorporam, em maior ou menor grau, os novos princípios de preservação nas suas práticas diárias, articuladas a outras práticas tradicionais de preservação que já eram executadas. Por outro, reinterpretam regras que conduzem a ambivalências e ambiguidades, ou mesmo as desobedecem como tentativa de deslegitimá-las, opondo-se ao conjunto de restrições impostas. (GEERTZ, 2006)

A busca do entendimento da capacidade dos indivíduos em aderir às novas normas referentes aos valores ambientais deve levar em consideração a confiança como sentimento de crença que vincula os indivíduos entre si e ao sistema social. As relações de confiança operam por meio da procura por reconhecimento, cujas referências estão fincadas nos costumes, na racionalidade e na percepção, influenciados pela cultura política de cada configuração específica do mundo globalizado. 
Assim, a descrença na lei contribui para os entraves na consolidação e efetivação de um modelo capaz de estabelecer acordos participativos. Essa deficiência tem raízes históricas, indicando que as contradições existentes na realidade brasileira "desenham um modo específico de percepção da reciprocidade e trocas entre cidadão e Estado, entre cidadão e normas sociais" (LANIADO, 2001a, p. 18). Estes argumentos evidenciam as dificuldades de superação da dualidade que se estabelece entre mundo formal e informal - o híbrido institucional a que se refere W. G. dos Santos -, o que compromete a estabilidade institucional e o funcionamento dos acordos.

É nesse contexto de fragilidade de uma cultura política democrática que a questão do conflito relativo à sobreposição territorial se situa. $O$ seu enfrentamento implica em uma articulação entre diferentes atores e instituições que, ainda que permeada de dificuldades, vem se constituindo em um novo paradigma de conservação, o qual considera o papel das populações locais nas estratégias sobre meio ambiente: a etnoconservação.

Em meio ao confronto de diferentes interesses e lógicas em um mesmo espaço social, revelando a multiplicidade de concepções territoriais e a fragilidade dos compromissos, que se faz importante retornar às reflexões sobre a forma que as políticas governamentais são implementadas e a maneira mais adequada para serem efetivadas. Segundo Santos (1994), para que tais políticas tenham sucesso, depende-se não apenas de qualidade técnica, mas também da capacidade de adequá-las às expectativas sociais implícitas, o que implica em articulações e parcerias.

\section{REFERÊNCIAS BIBLIOGRÁFICAS}

ALEXANDRE, A. F. Etnoconservação como política de meio ambiente no Brasil: desafios políticos de resistência e integração ao mundo globalizado. Agroecologia e Desenvolvimento Rural Sustentável, Porto Alegre, v. 3, n. 3, p. 55-64, 2002.

BAUMAN, Z. Identidade. Rio de Janeiro: Zahar, 2005.

BOURDIEU, P.; CHAMBOREDON, J-C.; PASSERON, J-C. Oficio de sociólogo: metodologia da pesquisa na sociologia. Petrópolis: Vozes, 2005.

BRASIL. Constituição (1988). Constituição da República Federativa do Brasil. Brasília, DF: Presidência da República, [2016]. Disponível em: http://www.planalto.gov.br/ccivil_03/ constituicao/constituicaocompilado.htm. Acesso em: 14 jan. 2018.

BRASIL. Decreto $n^{\circ} .98 .897$, de 30 de janeiro de 1990. Dispõe sobre as reservas extrativistas, e dá outras providências. Diário Oficial da União: Brasília, jan. 1990. 
Disponível em: http://www.planalto.gov.br/ccivil_03/decreto/antigos/d98897.htm. Acesso em: 14 jan. 2018.

BRASIL. Convenção da diversidade biológica, de 5 de junho de 1992. Disponível em: http://www.planalto.gov.br/ccivil_03/decreto/1998/anexos/and2519-98.pdf. Acesso em: 14 jan. 2018.

BRASIL. Decreto $\mathrm{n}^{\circ} .4 .340$, de 22 de agosto de 2002. Regulamenta artigos da Lei $\mathrm{n}^{\circ}$ 9.985, de 18 de julho de 2000, que dispõe sobre o Sistema Nacional de Unidades de Conservação da Natureza - SNUC, e dá outras providências. Diário Oficial da União: Brasília, ago. 2002b. Disponível em: http://www.planalto.gov.br/ccivil_03/ decreto/2002/d4340.htm. Acesso em: 14 jan. 2018.

BRASIL. Decreto ${ }^{\circ}$. 6.040, de 7 de fevereiro de 2007. Institui a Política Nacional de Desenvolvimento Sustentável dos Povos e Comunidades Tradicionais (PNPCT). Diário Oficial da União: Brasília, fev. 2007. Disponível em: http://www.planalto.gov.br/ ccivil_03/_ato2007-2010/2007/decreto/d6040.htm. Acesso em: 14 jan. 2018.

CASTELLS, M. O poder da identidade. A era da informação: economia, sociedade e cultura. São Paulo: Paz e Terra, 2013.

DIEGUES, A. C. (org.). Etnoconservação: novos rumos para a conservação da natureza nos trópicos. São Paulo: Hucitec: Nupaub-USP, 2000.

DIEGUES, A. C. O mito moderno da natureza intocada. São Paulo: Hucitec: Núcleo de Apoio à Pesquisa sobre Populações Humanas e Áreas Úmidas Brasileiras, 2001.

GEERTZ, C. O saber local: novos ensaios em antropologia interpretativa. Petrópolis: Vozes, 2006.

HABERMAS, J. A luta por reconhecimento no Estado democrático de direito. In: HABERMAS, J. A inclusão do outro. São Paulo: Loyola, 2004. p. 229-267.

HALL, S. A identidades cultural na pós-modernidade. Rio de Janeiro: DP\&A, 2005.

HOCSMAN, L. D. Estrategias territoriales, recampesinización y etnicidad en los andes de Argentina. Buenos Aires: Consejo Latinoamericano de Ciencias Sociales, 2011.

HOCSMAN, L. D. Agricultura familiar y descampesinización: nuevos sujetos para el desarrollo rural modernizante. Perspectivas Rurales. Nueva Época, Heredia, n. 25, p. 11-27, 2014.

HONNETH, A. Luta por reconhecimento: a gramática moral dos conflitos sociais. São Paulo: Ed. 34, 2011.

LANIADO, R. N. Troca e reciprocidade no campo da cultura política. Estado e Sociedade, Brasília, v. 16, n. 1-2, p. 222-244, 2001.

MATTOS, P. A sociologia política do reconhecimento. São Paulo: Annablume, 2006. 
RIBEIRO, M. T. F.; MILANI, C. R. Compreendendo a complexidade socioespacial contemporânea: o território como categoria de diálogo interdisciplinar. Salvador: Edufba, 2009.

ROCHA, J. C. S.; SERRA, O. Direito ambiental, conflitos socioambientais e comunidades tradicionais. Salvador: Edufba, 2015.

ROCHA, J. C. S. Direito, grupos étnicos e etnicidade. In: ROCHA, J. C.; SERRA, O. Direito ambiental, conflitos socioambientais e comunidades tradicionais. Salvador: Edufba, 2015. p. 13-30.

SANTILLI, J. Socioambientalismo e novos direitos: proteção jurídica à diversidade biológica e cultural. São Paulo: Peirópolis, 2005.

SANTOS, W. G. Fronteiras do estado mínimo: indicações sobre o híbrido institucional brasileiro. Caderno do IPRI, Brasília, n. 14, Brasília, p. 27-56, 1994.

SIQUEIRA, D.; PINTO, É. Política nacional de povos e comunidades tradicionais e reservas extrativistas. In: CONGRESSO BRASILEIRO DE SOCIOLOGIA, 13., 2007, Recife. Anais [...]. Recife: UFPE, 2007. p.13.

SOUZA, J. V. C. Congressos mundiais de parques nacionais da UICN (1962-2003): registros e reflexões sobre o surgimento de um novo paradigma para a conservação da natureza. 2013. Dissertação (Mestrado em Desenvolvimento Sustentável) - Centro de Desenvolvimento Sustentável, Universidade de Brasília, Brasília, 2013.

TALBOT, V. Termos de compromisso: histórico e perspectivas como estratégia para a gestão de conflitos em unidades de conservação federais. 2016. Dissertação (Mestrado Profissional em Biodiversidade em Unidades de Conservação) - Instituto de Pesquisas Jardim Botânico do Rio de Janeiro, Escola Nacional de Botânica Tropical, Rio de Janeiro, 2016.

VITALE, D. Democracia global e movimentos indígenas na cooperação sul-americana: um olhar para as comunidades amazônicas. In: VITALE, D.; KRAYCHETE, E. S. (org.). O Brasil e a cooperação Sul-Sul: dilemas e desafios da América do Sul. Salvador: Edufba, 2015. p. 20-50. 